\title{
Analysis of a Stirling engine in a waste heat recovery system with internal combustion engine
}

\author{
Francesco Catapano ${ }^{1}$, Carmela Perozziello*, and Bianca Maria Vaglieco $^{1}$ \\ ${ }^{1}$ Istituto di Scienze e Tecnologie per l'Energia e la Mobilità Sostenibili (STEMS) - Consiglio \\ Nazionale delle Ricerche, Via Guglielmo Marconi, 4, 80125 Napoli, Italy
}

\begin{abstract}
This work aims to study a Stirling engine (SE) used to recover the heat content of the exhaust gas from an internal combustion engine. The attention has been focused on the heat transfer between the exhaust gas and the working gas inside the heater. Experimental tests have been performed on a two-cylinder gamma-type Stirling engine coupled to a compression ignition engine using a thermally insulated pipe and a cap. A mechanical power of $0.275 \mathrm{~kW}$ at $900 \mathrm{rpm}$ SE rotational speed was obtained with a SE efficiency of $11.7 \%$. To investigate how the exhaust gas-heater interaction affects SE efficiency, a 3D model was developed by the authors. The cap-heater system was studied as a shell-and-tubes heat exchanger. Experimental values of temperature and velocity have been set as boundary conditions for the cap, while for the heater, pressure and velocity have been predicted using a $1 \mathrm{D}$ adiabatic model adjusted for SE geometry. The results showed that temperature distribution is not uniform in both cylinders, involving that the working pistons do not work in the same way. Therefore, to improve SE efficiency, a proper configuration of SE-CI engine coupling should be designed.
\end{abstract}

\section{Introduction}

The lively debate on environmental sustainability and reduction of fossil fuel consumption has enhanced the search for new energy production methods. In the last decades, the attention has been focused on waste heat recovery (WHR), that consists in converting the heat lost by thermal processes into additional mechanical work, especially for technologies in which a great quantity and quality of waste heat is available. In this respect, WHR has a great potential for internal combustion engines (ICE) because the exhaust gas contains about $30 \%-35 \%$ of total energy from fuel combustion [1]. In fact, even if new technologies are emerging, larger engines will continue to play a key role in the next few years for energy production, tankers, container ships, and heavy-duty systems. To overcome large dimensions, high weights and fluid problems of other systems (e.g, ORC systems, turbocharger turbine), Stirling engine (SE) could be a promising solution for ICE because of its compact design, easy maintenance, handling and safety, operating flexibility

${ }^{*}$ Corresponding author: carmela.perozziello@,virgilio.it 
over a wide temperature range and good efficiency [2-4]. Different examples of ICE-SE coupling can be found in literature, for both automotive and marine engines. Cullen et al. [5] studied SE efficiency as a WHR technology for an Otto cycle ICE in an automotive power plant in terms of energy. Experimental tests were performed on the Otto cycle engine, while a mathematical model was used to simulate a suitable SE. As a result, 30\% above the useful power of the ICE over the complete range of engine operating speeds was generated using the SE. Yutuc [6] investigated the possibility to insert a SE in the exhaust gas line of the propulsion engine onboard a tanker ship to provide the electric power for the switchboard on ship. A fuel saving of 1.5 tons per days with the lowest efficiency of $20 \%$ was proven. Alfarawi et al. [7] studied the use of a beta-type SE to drive the alternator in an ICE recovering the exhaust gas heat by an ideal adiabatic model to predict pressure, temperature and energy inside the SE. Moreover, an iterative analysis was carried out to modify heater and cooler geometry for the purpose of a uniform temperature distribution. Most of these studies are theoretically focused on the SE, above all for larger engines, for which is difficult to arrange an experimental layout. Moreover, no considerations about the interaction between heater and exhaust gas, that could be an interesting point of view when SE is coupled to an ICE, can be achieved.

In this work, the analysis of a real two-cylinder $\gamma$-type SE coupled to a compression ignition (CI) engine fed with commercial Diesel fuel has been performed via experimental and numerical approaches to recover the heat content of the exhaust gas. The selected configuration is able to simulate a larger engine in terms of exhaust gas temperature. A thermally insulated pipe and a cap (one inlet-one outlet) were used to hold the exhaust gas wrapping the heater, that consisted of two tubular heat exchangers, one for each cylinder in which helium flows as working gas. To investigate the exhaust gas-heater interaction that affects SE efficiency, a 3D model was developed in COMSOL Multiphysics ${ }^{\circledR}$ by the authors. The cap-heater system was studied as a shell-and-tubes heat exchanger. The balance equations of heat transfer and fluid flow interfaces have been solved using the nonisothermal flow predefined multiphysics coupling. The k- $\varepsilon$ turbulence model has been used to simulate the turbulent flow in the cap, while a laminar flow interface has been defined for the helium in the tubes. Experimental values of temperature and velocity have been set as boundary conditions for the cap, while for the heater, pressure and velocity have been predicted using well-established Urieli's 1D ideal adiabatic model adjusted for SE geometry, even if more complex analysis are reported in literature [8-11]. The combination of experimental and numerical methods presented in the work could be a valid procedure to design the better thermal source-SE coupling layout, optimizing the heat transfer.

\section{Material and Methods}

\subsection{Experimental set up}

The investigation has been performed on a two-cylinder gamma-type SE. A picture is shown in Fig. 1. The working piston and the displacer are mounted on the same crankshaft with a phase angle and they are arranged into two titled cylinders, that are linked by a connecting pipe. The heater consists of two tubular sets, one for each cylinder. In particular, each set is composed of 21 tubes made of steel with three different lengths. The regenerator is filled with a copper sponge with a high volumetric porosity equal to $96.5 \%$. The cooler is a finned water-jacketed heat exchanger. The working gas is Helium. The main engine specifications are reported in Table 1. 


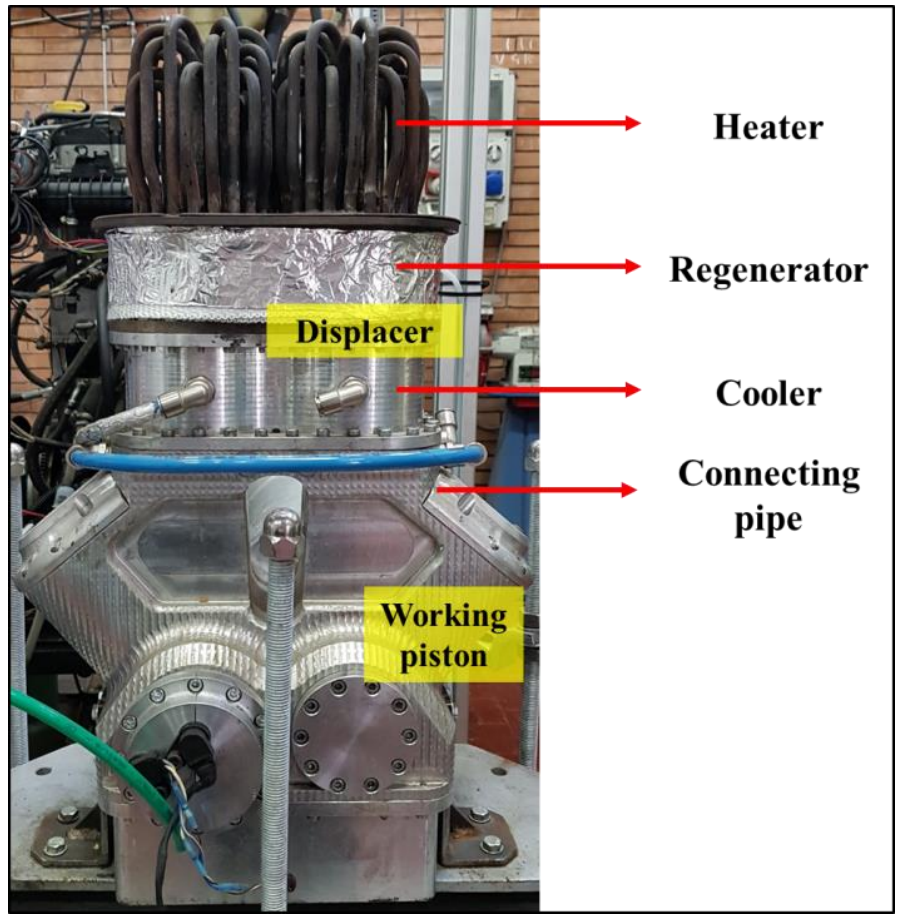

Fig. 1. A picture of the Stirling engine with the main components.

Table 1. Stirling engine specifications.

\begin{tabular}{|c|c|}
\hline Parameters & Values \\
\hline Number of cylinders & 2 \\
\hline Displacement & $310 \mathrm{~cm}^{3}$ \\
\hline Working piston bore & $75 \mathrm{~mm}$ \\
\hline Working piston stroke & $35 \mathrm{~mm}$ \\
\hline Displacer bore & $75 \mathrm{~mm}$ \\
\hline Displacer stroke & $50 \mathrm{~mm}$ \\
\hline
\end{tabular}

The SE was coupled to a three-cylinder, $1028 \mathrm{~cm}^{3}$, CI engine fed with commercial Diesel fuel equipped with modern Common Rail injection system. A thermally insulated pipe and a cap were used to carry and hold the exhaust gas wrapping the heater. The experimental apparatus is shown in Fig. 2. The cap is characterized by one inlet and one outlet on the smallest surfaces of the cap. The cap-heater system is similar to a shell-andtube heat exchanger. The hot exhaust gas coming from the engine, enters in the cap, heating up the helium that flows inside the tubes. Then, cold exhaust gas leaves the cap. A figure of the CI-SE coupling is shown in Fig. 2, while a detail picture for cap and heater is reported in Fig. 3. 


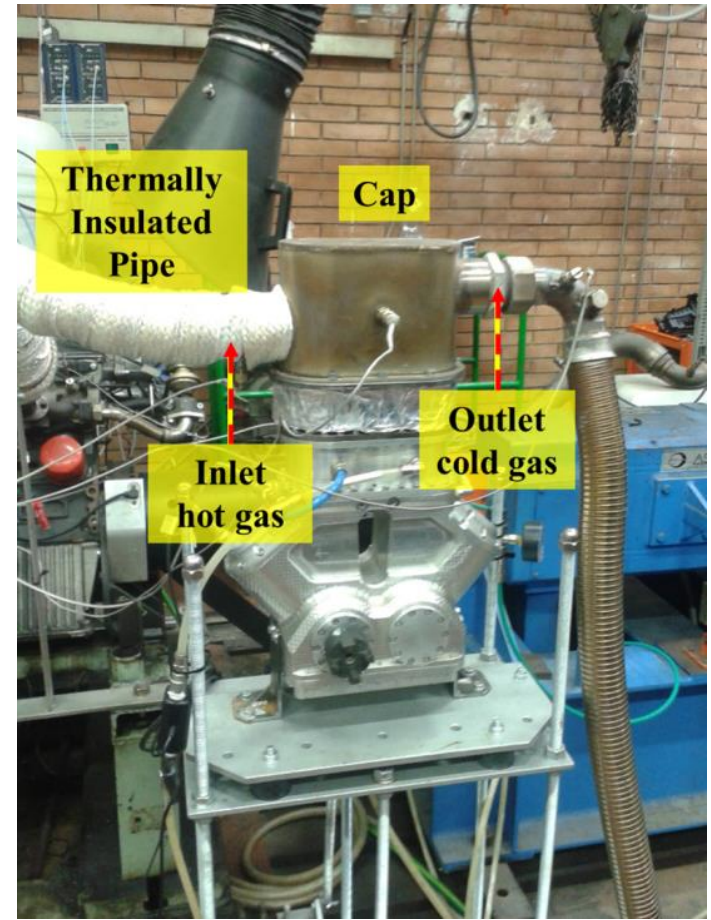

Fig. 2. Stirling engine - compression ignition engine coupling.

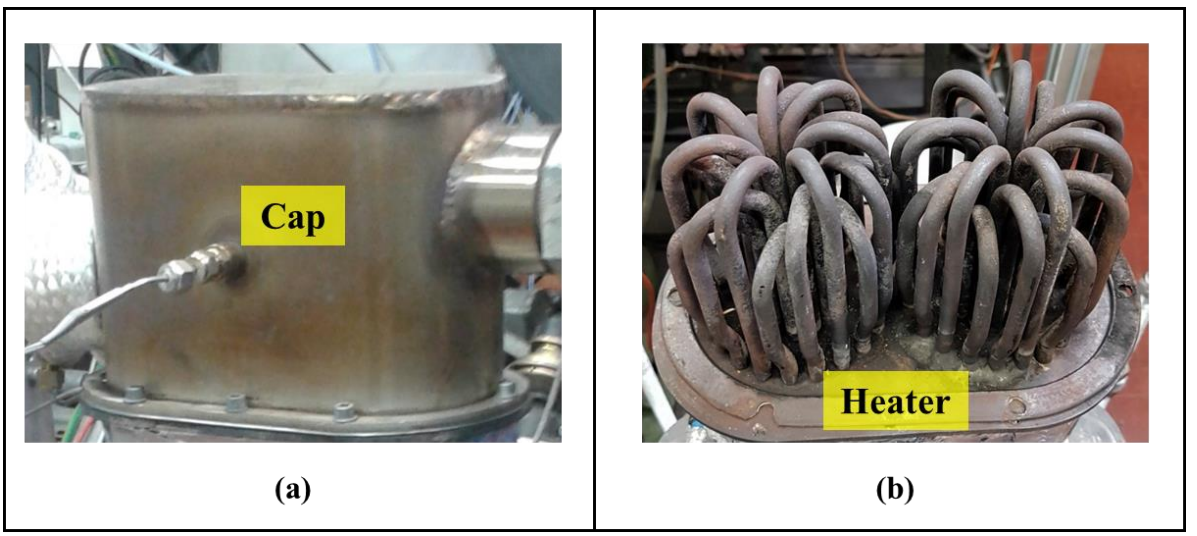

Fig. 3. Detail picture for cap (a) and heater (b).

CI-SE coupling was monitored a careful measurement system. The SE was equipped with three thermocouples to measure the exhaust gas temperatures at the inlet and the outlet, as well as inside the cap. This allowed to understand how the two tubular sets are heated by the exhaust gas. A manometer was used to set the working gas charge pressure at a fixed value of 7 bar. A flow meter and two thermocouples were used to control the flow rate and both the inlet and outlet temperatures of the cooling water. The electric power was generated coupling an electric generator to the engine crankshaft. Additional details and specifications are pointed out in [12]. Exhaust gas emissions $\left(\mathrm{CO}, \mathrm{CO}_{2}, \mathrm{HC}, \mathrm{NOx}\right)$ and the amount of soot were monitored in order to evaluate the influence of the heat exchanger on 
the CI engine performance. Engine out emissions were not affected by the introduction of the SE heat exchanger. Experimental tests were carried out at CI engine speed of $3400 \mathrm{rpm}$ (full load) at exhaust gas temperature $\left(T_{I N, \text { cap }}\right)$ equal to $833 \mathrm{~K}$. This value allowed to have the best performance of CI efficiency in WHR [13]. A warm up procedure was carried out for ten minutes to stabilize the CI engine operating conditions before running the SE (SE ${ }_{\text {off }}$ condition). Internal $\left(T_{\text {cap }}\right)$ and outlet temperatures $\left(T_{O U T, c a p}\right)$ for the exhaust gas, inlet $\left(T_{I N, \text { cool }}\right)$ and outlet temperatures $\left(T_{O U T, c o o l}\right)$ the mass flow rate $\left(m_{\text {cool }}\right)$ for the coolant were collected. After that, the $\mathrm{SE}$ was switched on ( $\mathrm{SE}_{\text {on }}$ condition) and the data were collected again. All the experimental results were digitalized and recorded at about $3 \mathrm{~Hz}$.

\subsection{Heat transfer model}

A 3D heat transfer model was developed by the authors in the finite element method (FEM) - based commercial software COMSOL Multiphysics ${ }^{\circledR}$ to investigate the heat transfer between exhaust gas and working gas inside the heater. The balance equations of heat transfer and fluid flow interfaces have been solved, using the non-isothermal flow predefined multiphysics coupling. The 3D geometry for the tubes reported in Fig. 4 shows inlet and outlet sections. Even if inlet and outlet sections change alternatively because the working gas flows twice through the tubes, during the heating phase, the working gas coming from the regenerator enters in the expansion space. Therefore, they are located on the outer and inner circle drawn by the tubes, respectively. For the cap, inlet and outlet sections are allocated according to the experimental apparatus.

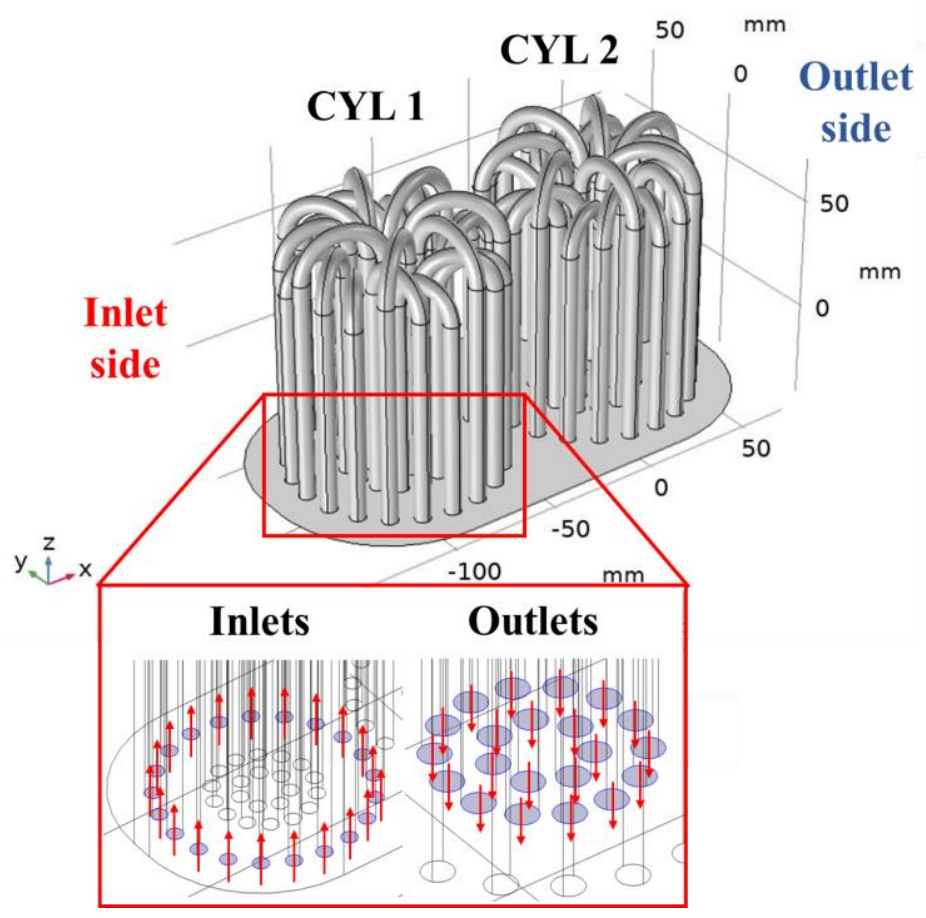

Fig. 4. Inlet and outlet sections for the tubes. 
All walls were made of structural steel and due to their low thickness, thermally thin approximation has been used. Moreover, a heat flux has been added on the walls, including the lower face, to simulate the experimental value of the heat rate loss by the cap. The exhaust gas in the cap was simulated by Nitrogen because it constitutes a large part of Diesel engine exhaust gas in percentage [14]. The k- $\varepsilon$ turbulence model has been used to simulate the turbulent flow in the cap, while a laminar flow interface has been defined for the helium in the tubes. The exhaust gas velocity $\left(v_{\text {exh }}\right)$, the inlet temperature $\left(T_{I N, \text { cap }}\right)$ and the outlet pressure ( $p_{\text {OUT,cap }}$ ) have been imposed as boundary conditions for the cap. These values are obtained from experimental tests. In particular, $v_{e x h}$ has been obtained by mass flow rate and density of the exhaust gas and the diameter of the exhaust pipe. For the heater, the regenerator temperature $\left(T_{r}\right)$, the velocity and the absolute pressure have been imposed at inlet sections, while normal flow and suppressed backflow have been set at outlet sections. The numerical values have been evaluated by the well-established 1D adiabatic model.

To resolve the flow field and the temperature distribution, a physics-controlled tetrahedral mesh of 1428376 elements has been generated. A stationary study has been performed, divided into two steps. First, only the turbulent flow interface in the cap has been solved. Then, all interfaces have been solved together, using the solution from the previous study as the initial value, resulting in lower computational time. The model has been validated against the achieved experimental data.

\subsubsection{D adiabatic model}

The values of boundary conditions have been evaluated using Urieli's 1D ideal adiabatic model $[15,16]$. It consists in dividing the SE into five control volume, i.e., compression space, cooler, regenerator, heater and expansion space, in which each component has a defined mass and temperature. It is mainly based on the adiabatic assumption for compression space and expansion space and the concept of conditional temperatures, introduced by Finkelstein [17], at compression space-cooler and heater and expansion space interfaces, according to mass flow direction. The other assumptions are reported below. The SE operates in quasi-steady state mode, maintaining a constant total mass and a uniform pressure. The working gas is considered an ideal gas. The regenerator temperature is assumed equal to the logarithmic mean between heater and cooler temperature.

The model has been properly modified according to SE geometry. In particular, the parameters related to the expansion $\left(V_{e}\right)$ and compression $\left(V_{c}\right)$ volumes have been replaced by the crankshaft mechanism equations [18-20]. They are expressed as follows:

$$
\begin{gathered}
V_{e}=V_{c l e}+V_{s w e} \\
V_{c}=V_{c l c}+V_{s w c}+2 c r_{d} \cdot A_{d}-V_{s w e}
\end{gathered}
$$

where $V_{c l}$ is the clearance volume, $c r$ is the crank radius and $A$ is the cross-sectional area. The subscript $\mathrm{d}$ is referred to the displacer, while $e$ and $c$ are referred to the expansion and compression spaces, respectively. The swept volumes $\left(V_{s w}\right)$ are given by:

$$
\begin{gathered}
V_{\text {swe }}=\left(\pi d_{d}^{2} / 4\right) \cdot c r_{d} \cdot\left\{1-\cos \theta+\left(1 / \lambda_{d}\right) \cdot\left[1-\left(1-\lambda_{d}^{2} \sin ^{2} \theta\right)^{1 / 2}\right]\right\} \\
V_{s w c}=\left(\pi d_{p}^{2} / 4\right) \cdot c r_{p} \cdot\left\{1-\cos (\theta-\varphi)+\left(1 / \lambda_{p}\right) \cdot\left[1-\left(1-\lambda_{p}^{2} \sin ^{2} \theta-\varphi\right)^{1 / 2}\right]\right\}
\end{gathered}
$$

where $\lambda$ is the crank radius - connecting rod length ratio, $\theta$ is the crank angle, $\varphi$ is the phase angle. The subscript $\mathrm{p}$ is referred to the working piston. 
To overcome the artful procedure for a gamma-type SE, the mass calculation has been calculated as the mean value of the mass at each crank angle as reported in [21, 22].

The curves depicted in Fig. 5(a) have been used for the pressure as inlet boundary condition in the heater tubes while, the velocity value has been evaluated as the mean of the absolute values of velocity curves reported in Fig. 5(b). The velocity of working gas at inlet section for each tube of the heater $\left(\mathrm{v}_{h}\right)$ is evaluated at the end of the ideal adiabatic analysis as:

$$
v_{h}=\omega \cdot\left[\left(m_{r h} / \rho_{r}\right) / 21\right] / A_{h}
$$

where $\omega$ is the rotational speed in $\mathrm{rad} / \mathrm{s}, m_{r h}$ is the total mass flow rate at regenerator-heater interface and $\rho_{r}$ is the density in the regenerator. All the variables are calculated every 10 ${ }^{\circ} \mathrm{CA}$. Because SE is a two-cylinder engine, the model has been applied separately to the first cylinder toward the inlet (CYL 1) and the second cylinder toward the outlet (CYL 2). The hot source temperature for CYL 1 has been set equal to $T_{I N, \text { cap }}$, while $T_{\text {cap }}$ in $\mathrm{SE}_{\text {on }}$ condition has been selected for CYL 2. The cold source temperature has been obtained as the mean value between $T_{I N, \text { cool }}$ and $T_{O U T, c o o l}$ in $\mathrm{SE}_{\text {on }}$ condition. The model has been validated checking that the mean pressure $\left(p_{\text {mean }}\right)$ represented by the horizontal line is equal to $p_{H e}$.

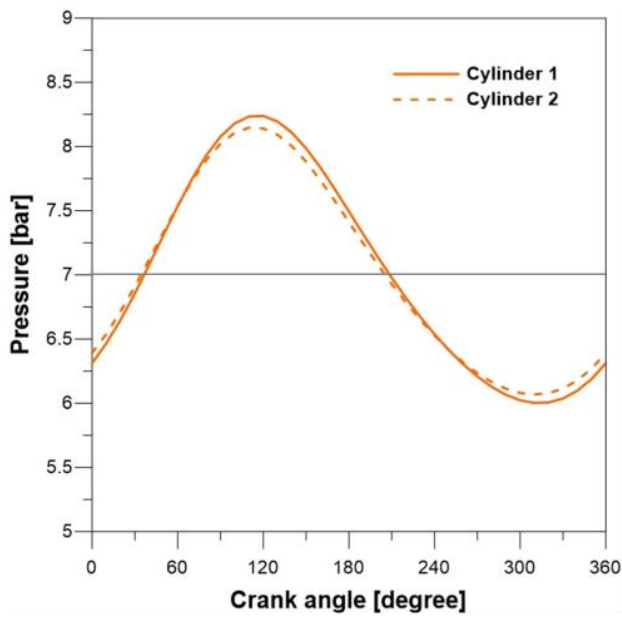

(a)

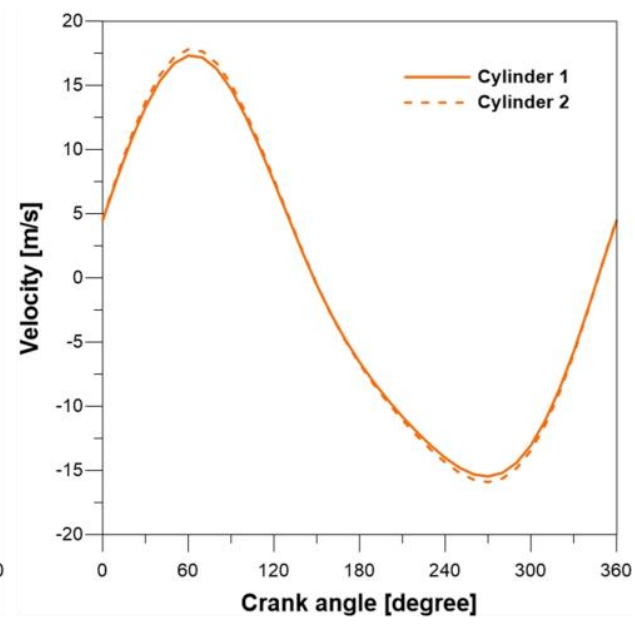

(b)

Fig. 5. Pressure (a) and velocity curves (b) for CYL 1 and CYL 2.

\section{Results}

\subsection{Experimental results}

Table 2 and Table 3 show experimental measurements in $\mathrm{SE}_{\text {off }}$ and $\mathrm{SE}_{\text {on }}$ conditions, respectively. By comparing $T_{I N, c a p}$ and $T_{O U T, c a p}$ in $\mathrm{SE}_{\text {off }}$ conditions, it can be noted that there is a difference of about $60 \mathrm{~K}$ even if the SE does not operate. This means that a percentage of exhaust gas heat content is lost in the surrounding environment. This quantity indicated as $Q_{\text {loss,cap }}$ is calculated by an energy balance on the cap as follows:

$$
Q_{\text {loss,cap }}=\left(m_{\text {exh }} / 3600\right) \cdot c_{p, e x h} \cdot\left(T_{I N, \text { cap }}-T_{\text {OUT, cap }}\right)_{\mathrm{SEoff}}
$$

where $c_{p, e x h}$ is the heat capacity at constant pressure for the exhaust gas at $T_{c a p}$ and $m_{\text {exh }}$ is the exhaust gas mass flow rate equal to the sum of fuel and air mass flow rate. The 
numerical value is reported in Table 4. When SE turns on, the exhaust gas heat transfer heat content is transferred to the working gas, resulting in a great difference between $T_{I N, \text { cap }}$ and $T_{O U T, \text { cap }}$ equal to about $135 \mathrm{~K}$. Because of inlet and outlet positions of the cap, the differences $T_{I N, \text { cap }}-T_{\text {cap }}$ and $T_{\text {cap }}-T_{O U T, \text { cap }}$ give a measure of the heat transfer in the first cylinder (CYL 1) and the second cylinder (CYL 2) in exhaust gas flow direction. In particular, $T_{c a p}$ is almost $120 \mathrm{~K}$ lower than $T_{I N, c a p}$, while the difference between $T_{c a p}$ and TOUT,cap is only $20 \mathrm{~K}$. These temperature values suggest that the waste heat of the exhaust gas does not distribute in the heater uniformly.

The mechanical power $\left(W_{\text {mec }}\right)$ produced by $\mathrm{SE}$ is $0.275 \mathrm{~kW}$ at $900 \mathrm{rpm}$. The heat rate recovered in $\mathrm{SE}_{\text {on }}$ condition $\left(Q_{e x h}\right)$ from the exhaust gas is given by:

$$
Q_{\text {exh }}=\left(m_{\text {exh }} / 3600\right) \cdot c_{p, e x h} \cdot\left(T_{I N, \text { cap }}-T_{O U T, c a p}\right)_{\mathrm{SEon}}
$$

and it is equal to $4.245 \mathrm{~kW}$. The difference between $Q_{\text {exh }}$ and $Q_{\text {loss,cap }}$ represents the effective heat rate available for the tubes. This value is reported in Table 4, with system efficiencies to evaluate SE performance as waste heat recovery system coupled to a CI engine. The thermal efficiency $\left(\eta_{t h}\right)$ denotes how much energy is recovered from the exhaust gas by the SE and it is given by:

$$
\eta_{t h}=\left(Q_{e f f} / Q_{e x h}\right) \cdot 100
$$

The SE efficiency $\left(\eta_{S E}\right)$ is calculated considering the thermal input and SE mechanical losses as

$$
\eta_{S E}=\left(W_{m e c} / Q_{e f f}\right) \cdot 100
$$

while the overall SE-CI system efficiency is given by $\eta_{t h}$ and $\eta_{S E}$ and in this application about $55.5 \%$ of the waste heat rate is recovered by the heater. However, $\eta_{S E}$ is equal to $11.7 \%$, resulting in a decrease of $\eta_{S E}$ up to $6.5 \%$. As mentioned before, the notable difference measured between $T_{I N, c a p}-T_{c a p}$ and $T_{c a p}-T_{O U T, c a p}$ involves that the heater temperature reaches two different values in CYL 1 and CYL 2. Because it is a two-cylinder $\mathrm{SE}$, the cylinders do not work similarly, resulting in a low $\eta_{S E}$ value. The experimental results suggest that the HE configuration significantly affects the WHR efficiency. Nevertheless, they do not give accurate information about the heat exchange occurring in the system. Therefore, in this work a 3D-1D modeling has been carried out in order to have a deep insight in the heat exchange between SE working gas and CI exhaust gas due to the HE geometry.

Table 2. Measurements for $\mathrm{SE}_{\text {off }}$ condition.

\begin{tabular}{|c|c|}
\hline Parameter & Value \\
\hline$T_{I N, \text { cap }}$ & $833.9 \mathrm{~K}$ \\
\hline$T_{\text {cap }}$ & $795.0 \mathrm{~K}$ \\
\hline$T_{\text {OUT,cap }}$ & $774.4 \mathrm{~K}$ \\
\hline$m_{\text {cool }}$ & $7.69 \mathrm{l} / \mathrm{min}$ \\
\hline$T_{I N, \text { cool }}$ & $288.7 \mathrm{~K}$ \\
\hline$T_{\text {OUT,cool }}$ & $289.4 \mathrm{~K}$ \\
\hline
\end{tabular}


Table 3. Measurements for SEon condition.

\begin{tabular}{|c|c|}
\hline Parameter & Value \\
\hline$T_{\text {IN,cap }}$ & $832.4 \mathrm{~K}$ \\
\hline$T_{\text {cap }}$ & $715.8 \mathrm{~K}$ \\
\hline$T_{\text {OUT,cap }}$ & $698.3 \mathrm{~K}$ \\
\hline$m_{\text {cool }}$ & $7.421 / \mathrm{min}$ \\
\hline$T_{\text {IN,cool }}$ & $288.5 \mathrm{~K}$ \\
\hline$T_{\text {OUT,cool }}$ & $294.8 \mathrm{~K}$ \\
\hline$W_{\text {mec }}$ & $0.275 \mathrm{~kW}$ \\
\hline
\end{tabular}

Table 4. Experimental results.

\begin{tabular}{|c|c|}
\hline Parameter & Value \\
\hline$Q_{\text {loss,cap }}$ & $1.890 \mathrm{~kW}$ \\
\hline$Q_{e x h}$ & $4.245 \mathrm{~kW}$ \\
\hline$Q_{\text {eff }}$ & $2.355 \mathrm{~kW}$ \\
\hline$\eta_{\text {th }}$ & $55.5 \%$ \\
\hline$\eta_{S E}$ & $11.7 \%$ \\
\hline$\eta$ & $6.5 \%$ \\
\hline
\end{tabular}

\subsection{Model results}

A summary of the boundary conditions with their respective values set according to experimental and numerical results are reported in Table 5. In particular, the experimental values needed for the simulation are $T_{I N, \text {,cap }}, Q_{\text {loss,cap }}, v_{\text {exh }}, p_{\text {OUT,cap }}$, for the cap, while $T_{r}$ and $v_{h}$, set for the tubes are obtained with the 1D model for CYL 1 and CYL 2.

Table 5. Input values for the model.

\begin{tabular}{|c|c|}
\hline Parameter & Value \\
\hline$T_{I N, \text { cap }}$ & $833 \mathrm{~K}$ \\
\hline$Q_{l o s s, c a p}$ & $1.890 \mathrm{~kW}$ \\
\hline$v_{e x h}$ & $50 \mathrm{~m} / \mathrm{s}$ \\
\hline poUT,cap & 0.9 bar \\
\hline$p_{\mathrm{He}}$ & 7 bar \\
\hline$T_{r}$ & $\begin{array}{l}516 \text { K (CYL 1); } \\
473 \text { K (CYL 2) }\end{array}$ \\
\hline$v_{h}$ & $\begin{array}{l}10.13 \mathrm{~m} / \mathrm{s}(\text { CYL } 1) \\
10.40 \mathrm{~m} / \mathrm{s} \text { (CYL 2) }\end{array}$ \\
\hline
\end{tabular}


The 3D heat transfer model has been validated against experimental value of TouT,cap. The average temperature of Nitrogen, that simulates the exhaust gas, has been calculated at the end of the simulation. It decreases from $832 \mathrm{~K}$ at inlet section up to $719 \mathrm{~K}$ at outlet section. This is in a good agreement with the experimental value $(698 \mathrm{~K})$, with an acceptable degree of accuracy ( $3 \%$ of error). Therefore, model results can be used to predict how temperature and velocity change in SE heater, that is an information which is not achieved experimentally.

The results in terms of velocity streamlines and temperature distribution for the heater are reported in Fig. 6. The streamlines color represents the temperature values in $\mathrm{K}$ according to the color bar on the right. The most important remark is that the temperature distribution is very different between the two banks of the SE. In particular, the average outlet temperature for CYL 1 is $564 \mathrm{~K}$, while it is equal to $494 \mathrm{~K}$ for CYL 2. In the same way, the volume average temperature is higher for CYL $1(546 \mathrm{~K})$ than for CYL 2 (489 K). Therefore, the heat rate to the Helium in the SE heater is higher for the Cyl1, about 1.25 $\mathrm{kW}$, than Cyl 2 that exchanged only about the half of heat, $0.64 \mathrm{~kW}$.

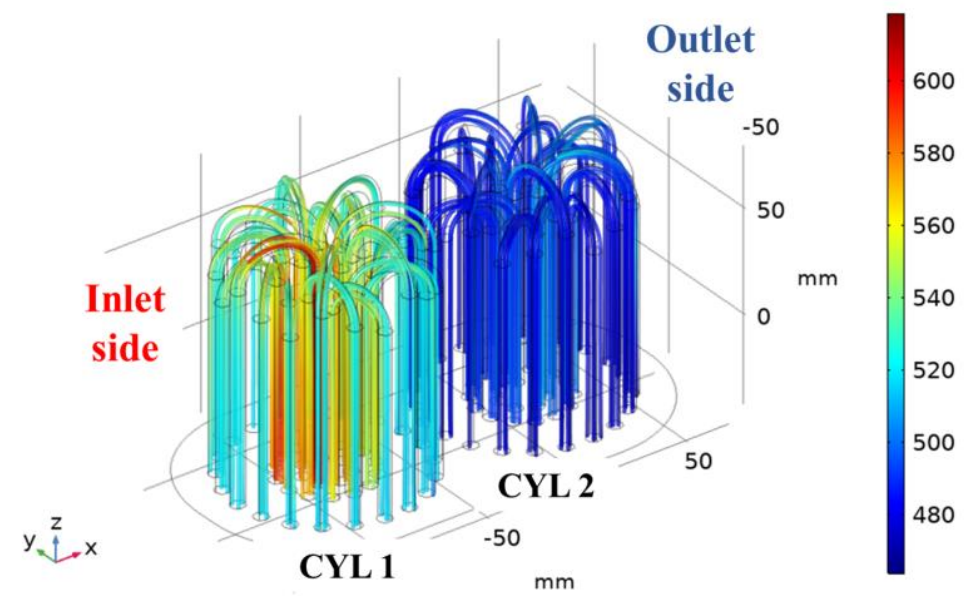

Fig. 6. Temperature distribution in $\mathrm{K}$ according to the color bar on the right using streamlines representation for the heater.

To better analyse what happens in the cap, the temperature distribution and the velocity field on the middle yz-planes at $\mathrm{x}=-38 \mathrm{~mm}$ is reported in Fig. 7(a) and Fig. 7(b). The temperature decreases along z-axis in the cap. However, Nitrogen temperature remains about equal to the inlet value in the upper part of the cap. This is due to the location of inlet and outlet sections in the cap which does not ensure to exhaust gas entering and moving around the heater sufficiently. In fact, according to Fig. 7(b), where the velocity scale is limited to $0-5 \mathrm{~m} / \mathrm{s}$ it is possible to see that there is no great turbulence before CYL 2. As a consequence, the forced convection mechanism is strongly prevented, resulting in a not efficient enough heat transfer between the exhaust gas and the working gas in the tubes of CYL 2. 


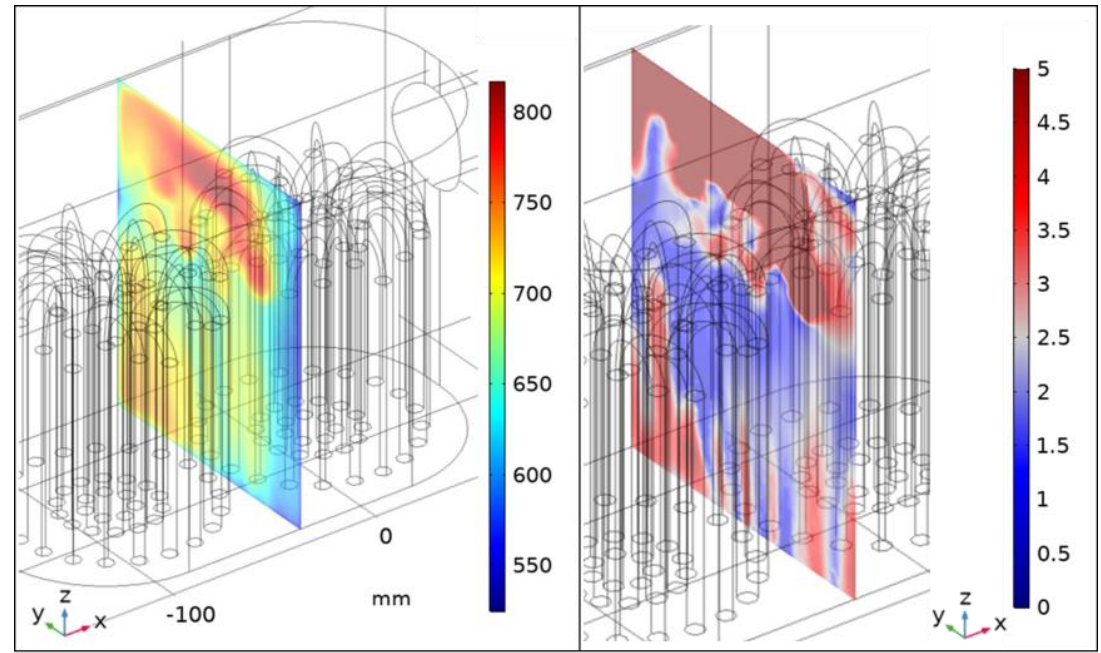

(a)

(b)

Fig. 7. Temperature distribution (a) and velocity field (b) on the middle yz-plane at $x=-38 \mathrm{~mm}$.

The results show that the temperature distribution was not uniformly in both the heat exchangers. Because of the inlet position of the cap, the exhaust gas impacts on the first tubular set (closer to inlet section), transferring the heat to this part; then the already cooler gas impacts on the other tubes (closer to outlet section), transferring the residual heat. This implies that the two pistons do to work in the same way, resulting in a low efficiency. The 3D model results confirm the assumption achieved by experimental results, by adding more details about heat transfer properties between exhaust gas and working gas and on a better geometrical configuration. To improve SE efficiency, a proper configuration of SE-CI engine coupling should be designed, making sure that both the heat exchangers are heated homogeneously. Inlet and outlet sections should be located on the cap surface in a symmetric position with respect to the two tubular heat exchangers. That is why the combination of experimental and 1D-3D model approach becomes important to improve SE efficiency in WHR applications.

\section{Conclusions}

The analysis of a two-cylinder gamma-type SE coupled to a compression ignition engine has been performed via experimental and numerical approaches to recover the heat content of the exhaust gas. A thermally insulated pipe and a cap with one inlet and one outlet were used to hold the exhaust gas wrapping the heater, that consisted of two tubular heat exchangers. Experimental tests were carried out at the CI engine speed of $3400 \mathrm{rpm}$ (full load) to work with the maximum CI efficiency in WHR, monitoring the main quantities among which the temperatures across the cap of the exhaust gas at inlet, middle and outlet sections. A mechanical power of $0.275 \mathrm{~kW}$ at $900 \mathrm{rpm}$ SE rotational speed was obtained with a SE efficiency of $11.7 \%$.

Moreover, a 3D-1D simplified model of the system has been developed in order to deeply analyse the heat exchange in the shell-and-tube HE. The proposed model gives quite accurate results an allowed to have a deep inside the heat exchange between the SE working gas and the CI exhaust gas. The results shown that the temperature distribution was not uniformly in both the tube bundles due to the inlet position of the HE cap, resulting 
in a not-optimal SE operation. Therefore, a bad exhaust gas-heater interaction affects SE efficiency significantly.

The proposed numerical methods presented in the work give quite accurate results and can be useful to improve the heat transfer in the WHR system, optimizing the design of the thermal source-SE coupling layout. These consideration and methodology, achieved on a small laboratory prototype, could be extended to larger engines, with the necessary modification due to the different scale factors.

\section{Acknowledgment}

The authors would like to thank Carlo Rossi and Bruno Sgammato for their support in experimental activities.

\section{References}

1. AT. Hoang, Waste heat recovery from diesel engines based on Organic Rankine Cycle, Appl. En. 231, 138-66 (2018).

2. L. Kuban, J. Stempka, A. Tyliszczak, A 3D-CFD study of a $\gamma$-type Stirling engine, Energy 169, 142-59 (2019).

3. G. Walker, Stirling engines, Oxford: Clarendon Press; New York: Oxford University Press, (1980)

4. H. Hachem, R. Gheith, F. Aloui, SB. Nasrallah, Technological challenges and optimization efforts of the Stirling machine: A review, En. Conv. Man. 171, 1365-87 (2018).

5. B. Cullen, J. Mc Govern, Energy system feasibility study of an Otto cycle/Stirling cycle hybrid automotive engine, Energy 35 1017-23 (2010).

6. WE. Yutuc, A Study on the Use of a Stirling Engine generator to reduce fuel oil consumption onboard a tanker ship, Jour. Engin. Appl. Scien. 11(9) 2044-49 (2016).

7. S. Alfarawi, M.Webb-Martin, S. Mahmoud, RK. AL-Dadah, Thermal analysis of stirling engine to power automotive alternator using heat from exhaust gases, En. Proc. 61, 2395-98, 6th International Conference on Applied Energy - ICAE2014 (2014).

8. S. Alfarawi, R. AL-Dadah, S. Mahmoud, Enhanced thermodynamic modelling of a gamma-type Stirling engine, Appl. Therm. Eng. 106, 1380-90 (2016).

9. M. Torres García, E. Carvajal Trujillo, JA. Vélez Godiño, D. Sánchez Martínez, Thermodynamic model for performance analysis of a stirling engine prototype, Energies 11, 2655 (2018).

10. R. Li, L. Grosu, W. Li. New polytropic model to predict the performance of beta and gamma type Stirling engine, Energy 128, 62-76 (2017).

11. A. Sowale, AJ. Kolios, B. Fidalgo, T. Somorin, A Parker, L. Williams, M. Collins, E. McAdam, S. Tyrrel. Thermodynamic analysis of a gamma type Stirling engine in an energy recovery system, En. Conv. Man. 165, 528-40 (2018). 
12. C. Perozziello, Experimental and numerical study of a stirling engine for waste heat recovery from internal combustion engine, ( $\mathrm{PhD}$ Thesis, University Parthenope, Naples-Italy 2020).

13. A. Magno, E. Mancaruso, BM. Vaglieco, Effect of both blended and pure biodiesel on waste heat recovery potentiality and exhaust emissions of a small CI (compression) engine, Energy 86, 661-71 (2015).

14. İA. Reşitoğlu, K. Altinişik, A. Keskin, The pollutant emissions from diesel engine vehicles and exhaust aftertreatment systems, Clean Techn. En. Pol. 17, 15-27 (2015).

15. https://www.ohio.edu/mechanical/stirling/index.html [accessed 30 April 2020].

16. I. Urieli, DM. Berchowitz, Stirling cycle engine analysis, (Bristol, NY; Adam Hilger LTD; Taylor \& Francis; Abingdon, UK, (1984).

17. T. Finkelstein, Insights into the thermodynamics of Stirling cycle machines, IAA-943951-CP, 1829-34 (1994).

18. J. Egas, DM. Clucas, Stirling engine configuration selection. Energies, 11, 584 (2018).

19. S. Alfarawi, Modelling and optimization of high temperature difference (htd) gammatype stirling engine prototype, ( $\mathrm{PhD}$ thesis, University of Birmingham, 2017).

20. A. Wagner, Calculations and experiments on gamma-type stirling engines, (Cardiff University, 2008).

21. CP. Speer, DA. Miller, CJA. Stumpf, JP. Michaud, DS. Nobes, Modification of an ST05G-CNC Stirling engine to use a low temperature heat source, (15 ${ }^{\circ}$ International Energy Conversion Engineering Conference, 10-12 July 2017, Atlanta).

22. CP. Speer, Modifications to reduce the minimum thermal source temperature of the ST05G-CNC Stirling engine, (Department of Mechanical Engineering, University of Alberta, 2018). 